\title{
PENGEMBANGAN MEDIA PEMBELAJARAN BERBASIS TIGA LEVEL REPRESENTASI MENGGUNAKAN PREZI PADA MATERI KESETIMBANGAN KIMIA KELAS XI SMA/MA
}

\author{
Sri Rizka Fadila Guci ${ }^{1)}$ Rahadian Zainul ${ }^{2)}$ Minda Azhar ${ }^{3 *}$ \\ 1) Jurusan Kimia, FMIPA, Universitas Negeri Padang \\ 2) Jurusan Kimia, FMIPA, Universitas Negeri Padang \\ 3)Jurusan Kimia, FMIPA, Universitas Negeri Padang \\ J1. Prof. Hamka Air Tawar Padang \\ Email ${ }^{3 *}$ : minda@fmipa.unp.ac.id
}

\begin{abstract}
S
Learning media based on three levels representation using Prezi is an alternative learning media that is more interesting and dynamic. Chemical equilibrium material that is difficult to understand by students will be overcome by using this learning media. This research is aimed to develop learning media based on three levels of representation using Prezi and to test the validity and practice of learning media developed. This research is a research development of Research and Development (R \& D) by using 4-D development model consisting of 4 stages namely (1) define (definition stage), (2) design (design stage), (3) develop (development stage) and (4) disseminate (stage of dissemination). This study is limited to the development stage. The research instrument used in the form of a questionnaire in the form of validity sheet and practicality. From the results of validity test obtained the average value of kappa moment of 0.89 with the category of very high prevalence. Practicality test results on the students obtained the average value of kappa moment of 0.80 with high practicality category, while the teachers obtained by 0.92 with the category of very high practicality. Based on the result of the research, it can be concluded to produce learning media based on three levels of reprsentation using Prezi on chemical equilibrium material is valid and practical, so it can be used in the learning activity of chemistry class XI in SMA / MA.
\end{abstract}

Keywords: Learning media, Three Level Representations, Prezi, Chemical Equilibrium, Model 4-D

\section{PENDAHULUAN}

Karakteristik yang dimiliki ilmu kimia ialah sebagian besar konsep-konsepnya bersifat abstrak (Sirhan, 2007). Sifat ilmu kimia yang abstrak menyebabkan ilmu kimia cenderung menjadi pelajaran yang sulit dipahami bagi kebanyakan siswa. Pembelajaran kimia yang kompleks dan abstrak membuat siswa sulit dalam belajar (Chandrasegaran et al., 2007).

Salah satu cara mengatasi masalah pembelajaran kimia adalah dengan menggunakan tiga level representasi yaitu level makroskopik, level submikroskopik dan level simbolik. Representasi makroskopik merupakan level konkret, dimana pada level ini siswa mengamati langsung fenomena yang terjadi, baik melalui percobaan yang dilakukan atau fenomena yang terjadi pada kehidupan seharihari.
Representasi submikroskopik merupakan level abstrak yang menjelaskan fenomena makroskopik. Representasi ini memberikan penjelasan pada level partikel dimana materi digambarkan sebagai susunan dari atom-atom, molekul-molekul, ion-ion. Level representasi simbolik digunakan untuk merepresentasikan fenomena makroskopik dengan menggunakan persamaan kimia, persamaan matematika, grafik, mekanisme reaksi dan analogi-analogi. Ketiga level tersebut dikenal dengan tiga level representasi yang dalam kimia dikenal sebagai tiga level representasi kimia.

Level representasi submikroskopik dan simbolik, keduanya dibutuhkan untuk menjelaskan fenomena makroskopik, sehingga penjelasan konsep kimia menjadi lengkap dan bermakna (Tuysuz, 2011). Hubungan timbal balik antara tiga level representasi kimia tersebut dapat menunjukkan pemahaman yang 
utuh dari suatu konsep kimia. Oleh karena itu, tiga level representasi sangat penting digunakan dalam pembelajaran kimia untuk membantu siswa belajar kimia dengan lebih bermakna.

Salah satu materi kimia yang sulit dipahami siswa adalah kesetimbangan kimia karena sebagian besar konsep-konsep pada materi ini bersifat abstrak. Kesetimbangan kimia merupakan topik yang paling sulit dalam pembelajaran kimia. Kesulitan tersebut disebabkan sebagian besar konsep-konsep dalam topik kesetimbangan kimia merupakan konsep abstrak, seperti konsep setimbang dan pergeseran kesetimbangan (Lukum, 2015).

Berdasarkan hasil wawancara dan pemberian angket yang dilakukan pada dua SMA di Padang ditemukan bahwa separoh dari siswa di kelas XII MIA/IPA masih mengalami kesulitan memahami materi kesetimbangan kimia. Selain itu, siswa sulit membuat transformasi dari representasi simbolik ke submikroskopik. Hal ini menandakan tingkat pemahaman konsep kimia siswa belum mampu menghubungkan ketiga level representasi kimia dengan benar pada materi kesetimbangan kimia.

Selain itu, hasil penelitian pada materi reaksi kimia menunjukkan bahwa tidak seorang partsipanpun yang menunjukkan pemahaman yang jelas pada karakteristik submikroskopik dari ion-ion poliatom serta terdapat partisipan yang memiliki beberapa kesalahpahaman pada aspek submikroskopik yang substansial pada reaksi kimia (Hinton \& Nakhteh, 1999). Pada materi Hukum hukum Dasar Kimia telah pernah dilakukan pengembangan dengan menggunakan Prezi (Zainul,R., Handayani, 2018).

Media pembelajaran bisa menjadi solusi dalam mengatasi permasalahan di atas. Media pembelajaran yang sering digunakan adalah PowerPoint. PowerPoint merupakan software presentasi yang disediakan oleh Microsfot Office, yang dalam penggunaannya pada komputer pengguna telah terinstal Microsoft Office. Selain PowerPoint, terdapat software lain yang dapat digunakan sebagai media pembelajaran yaitu Prezi. Media berbasis teknologi lain yang kini juga kerap dikembangkan adalah berbasis Android (Zainul, R., Jannah, 2018).

Prezi merupakan software presentasi yang dirancang agar dapat menampilkan media visual, audio maupun animasi. Prezi dikembangkan pada tahun 2007 dan dipublikasi pada tahun 2009 oleh seorang seniman yang berasal dari Hungaria yaitu Adam SomlaiFischer dan seorang ahli komputer, Peter Halacsy (Krause, 2014). Media pembelajaran menggunakan Prezi menarik bagi siswa (Epinur, 2014).

\section{METODE PENELITIAN}

Jenis penelitian yang dilakukan adalah penelitian dan pengembangan atau Research and Devolepment $(R \& D)$. Penelitian ini merupakan metode penelitian yang digunakan untuk mengembangkan atau menghasilkan produk tertentu, dan menguji keefektifan produk tersebut (Sugiyono, 2011). Instrument penelitian berupa angket yang terdiri dari lembar validitas dan lembar praktikalitas. Data yang diperoleh dianalisis menggunakan momen kappa (Boslaugh, 2008).

$$
\text { Moment kappa }(\mathrm{k})=\frac{\rho-\rho_{\mathrm{e}}}{1-\rho_{\mathrm{e}}}
$$

Keterangan:

$k=$ Moment kappa yang menunjukkan validitas produk.

$\rho=$ Proporsi yang terealisasi, dihitung dengan cara jumlah nilai yang diberi oleh validator dibagi jumlah nilai maksimal.

$\rho_{\mathrm{e}}=$ Proporsi yang tidak terealisasi, dihitung dengan cara jumlah nilai maksimal dikurangi dengan jumlah nilai total yang diberi validator dibagi jumlah nilai maksimal.

Tabel 1. Kategori Keputusan berdasarkan Moment Kappa(k)

\begin{tabular}{|c|c|}
\hline Interval & Kategori \\
\hline $0,81-1,00$ & Sangat tinggi \\
\hline $0,61-0,80$ & Tinggi \\
\hline $0,41-0,60$ & Sedang \\
\hline $0,21-0,40$ & Rendah \\
\hline $0,01-0,20$ & Sangat rendah \\
\hline$\leq 0,00$ & Tidak valid \\
\hline
\end{tabular}

(Boslaugh, 2008)

Media pembelajaran berbasis tiga level representasi kimia menggunakan Prezi dirancang dengan dasar model 4- $D$ (four $D$ models). Model $4-D$ terdiri dari 4 tahap 
pengembangan yaitu define, design, develop, dan disseminate (Trianto, 2012). Penelitian ini hanya sampai pada tahap develop.

Pada tahap define (pendefinisian) dilakukan 5 analisis yaitu analisis ujung depan, analisis siswa, analisis tugas, dan analisis konsep serta analisis tujuan pembelajaran. Analisis ujung depan bertujuan untuk mengetahui dan menetapkan masalah dasar yang dihadapi guru dan siswa dalam pembelajaran kimia pada materi kesetimbangan kimia. Dari analisis ini diperoleh gambaran fakta permasalahan dan alternatif penyelesaian masalah.

a. Analisis ujung depan

Analisis ujung depan dilakukan dengan mewawancarai beberapa orang guru kimia SMA di kota Padang.

b. Analisis siswa

Analisis siswa merupakan tela'ah karakteristik siswa yang sesuai dengan desain pengembangan perangkat pembelajaran. Identifikasi ini dilakukan untuk mengetahui karakteristik siswa, antara lain kemampuan akademik dan motivasi belajar. Analisis dilakukan dengan memberikan angket kepada siswa dan wawancara terhadap guru kimia.

c. Analisis tugas

Analisis tugas merupakan kumpulan prosedural untuk menentukan isi dalam media pembelajaran berbasis tiga level representasi kimia menggunakan Prezi. Pada analisis tugas dilakukan analisis Kompetensi Inti (KI) dan Kompetensi Dasar (KD) pada materi kesetimbangan kimia.

d. Analisis konsep

Analisis konsep dilakukan untuk mengidentifikasi konsep-konsep utama yang dijabarkan dalam media pembelajaran yang dikembangkan untuk materi kesetimbangan kimia.

e. Analisis tujuan pembelajaran

Analisis tujuan pembelajaran dilakukan dengan cara menganalisis kompetensi dasar (KD) yang diuraikan menjadi beberapa indikator pembelajaran. Indikator pembelajaran diuraikan menjadi beberapa tujuan pembelajaran yang harus dicapai dalam proses pembelajaran.

Berdasarkan hasil analisis pada tahap define selanjutnya dilakukan tahap design (perancangan). Tahap design bertujuan untuk merancang media pembelajaran berbasis tiga level representasi kimia menggunakan Prezi.

Tahap akhir penelitian ini adalah tahap develop (pengembangan). Tahap ini bertujuan untuk menghasilkan media pembelajaran yang valid. Tahap ini terdiri dari tiga tahap yaitu uji validitas, revisi dan uji praktikalitas media pembelajan berbasis tiga level representasi menggunakan Prezi pada materi kesetimbangan kimia kelas XI SMA/MA.

\section{HASIL DAN PEMBAHASAN}

Penelitian ini menggunakan model pengembangan 4-D. Tahap pengembangannya sebagai berikut:

\section{Tahap define (pendefinisian)}

Pada tahap pendefinisian diperoleh 5 data yaitu data analisis ujung depan, analisis siswa, analisis tugas, analisis konsep, dan analisis tujuan pembelajaran.

a. Analisis ujung depan

Pada analisis ujung depan diperoleh data bahwa sebagian besar siswa masih kesulitan memahami konsep kesetimbangan kimia karena sifatnya yang abstrak. Siswa belum mampu mengaitkan ketiga level representasi kimia pada materi kesetimbangan kimia. Pembelajaran kimia hendaknya ditekankan pada tiga level representasi kimia (makroskopik, submikroskopik, dan simbolik). Pemahaman seseorang terhadap kimia ditentukan oleh kemampuannya dalam mentransfer dan mengaitkan ketiga level representasi kimia tersebut (Sunyono, 2013).

Media pembelajaran yang sering digunakan oleh guru pada materi kesetimbangan kimia adalah buku teks, LKS dan PowerPoint. Media tersebut belum membantu siswa agar mampu mengaitkan ketiga level representasi kimia pada materi kesetimbangan kimia. Oleh sebab itu, perlu dikembangkan media pembelajaran yang dapat membantu siswa mengaitkan ketiga level representasi kimia tersebut.

b. Analisis siswa

Analisis siswa dilakukan berdasarkan lembar angket yang diberikan kepada siswa. Data yang diproleh adalah siswa lebih suka belajar menggunakan media yang menarik, seperti menggunakan video, animasi serta tampilan media yang berwarna-warni. Salah 
satu strategi dalam memfasilitasi proses pembelajaran adalah dengan warna karena warna mampu memotivasi siswa dalam belajar (Olurinola, 2015). Informasi tentang karakteristik yang dimiliki siswa akan memudahkan perancangan media pembelajaran yang cocok untuk siswa.

c. Analisis tugas

Analisis tugas dilakukan berdasarkan analisis Kompetensi Dasar (KD) pada silabus kurikulum 2013. Kompetensi dasar pada materi kesetimbangan kimia adalah sebagai berikut ini

3.8. Menganalisis faktor-faktor yang mempengaruhi pergeseran arah kesetimbangan yang diterapkan dalam industri.

3.9. Menentukan hubungan kuantitatif antara pereaksi dengan hasil reaksi dari suatu reaksi kesetimbangan.

Materi kesetimbangan kimia yang tercakup pada KD 3.8 dan 3.9 dapat dijabarkan menjadi beberapa indikator pembelajaran:

1. Menjelaskan pengertian kesetimbangan dan setimbang

2. Menjelaskan faktor-faktor yang mempengaruhi pergeseran kesetimbangan

3. Meramalkan arah pergeseran kesetimbangan menggunakan Azas Le Chatelier

4. Menganalisis pengaruh perubahan konsentrasi, suhu, tekanan dan volume pada pergeseran kesetimbangan

5. Menuliskan tetapan kesetimbangan $\left(\mathrm{K}_{\mathrm{c}}\right)$ untuk kesetimbangan homogen dan kesetimbangan heterogen

6. Menghitung harga $\mathrm{K}_{\mathrm{c}}$ berdasarkan konsentrasi zat dalam kesetimbangan

7. Menghitung harga $K_{p}$ berdasarkan tekanan parsial gas pereaksi dan hasil reaksi pada keadaan setimbang

8. Menentukan hubungan $\mathrm{K}_{\mathrm{c}}$ dengan $\mathrm{K}_{\mathrm{p}}$

9. Menghitung harga $K_{c}$ berdasarkan $K_{p}$ atau sebaliknya

10.Menentukan harga $\mathrm{K}_{\mathrm{c}}$ atau $\mathrm{K}_{\mathrm{p}}$ berdasarkan hasil reaksi pada keadaan setimbang

d. Analisis konsep

Konsep-konsep pada materi ini dianalisis berdasarkan karakteristik materi yaitu dengan mengelompokkan materi yang bersifat faktual, konseptual dan prosedural.

e. Analisis tujuan pembelajaran

Tujuan pembelajaran materi kesetimbangan kimia yang dicapai menggunakan media pembelajaran berbasis tiga level representasi menggunakan Prezi sebagai berikut :

1. Siswa mampu menjelaskan pengertian kesetimbangan dan setimbang

2. Siswa mampu menjelaskan faktor-faktor yang mempengaruhi pergeseran kesetimbangan kimia

3. Siswa mampu menentukan arah pergeseran kesetimbangan dengan menggunakan Azas Le Chatelier

4. Siswa mampu menganalisis pengaruh perubahan konsentrasi, suhu, tekanan dan volume pada pergeseran kesetim-bangan kimia suatu reaksi

5. Siswa mampu menuliskan tetapan kesetimbangan $\left(\mathrm{K}_{\mathrm{c}}\right)$ untuk kesetimbangan homogen dan kesetimbangan heterogen

6. Siswa mampu menghitung harga $\mathrm{K}_{\mathrm{c}}$ berdasarkan konsentrasi zat dalam kesetimbangan

7. Siswa mampu menghitung harga $K_{p}$ berdasarkan tekanan parsial gas pereaksi dan hasil reaksi pada keadaan setimbang

8. Siswa mampu menentukan hubungan antara $\mathrm{K}_{\mathrm{c}}$ dengan $\mathrm{K}_{\mathrm{p}}$ pada suatu reaksi

9. Siswa mampu menghitung harga $\mathrm{K}_{\mathrm{c}}$ berdasarkan $\mathrm{K}_{\mathrm{p}}$ atau sebaliknya

10. Siswa mampu menentukan harga $\mathrm{K}_{\mathrm{c}}$ atau $\mathrm{K}_{\mathrm{p}}$ berdasarkan hasil reaksi pada keadaan setimbang

\section{Tahap design (perancangan)}

Media pembelajaran berbasis tiga level representasi menggunakan Prezi yang telah dirancang terdiri dari: Home, Petunjuk penggunaan, Identitas media, , Kompetensi inti, Kompetensi dasar, Indikator, Tujuan pembelajaran, Materi, Soal latihan, dan Soal evaluasi. Point-point penting pada media pembelajaran ini dimuat pada Gambar 1 sampai Gambar 7.

\section{a. Home}

Tampilan awal media pembelajaran ini adalah kesulurahan isi media. Tampilan ini dinamakan home (Gambar 1).

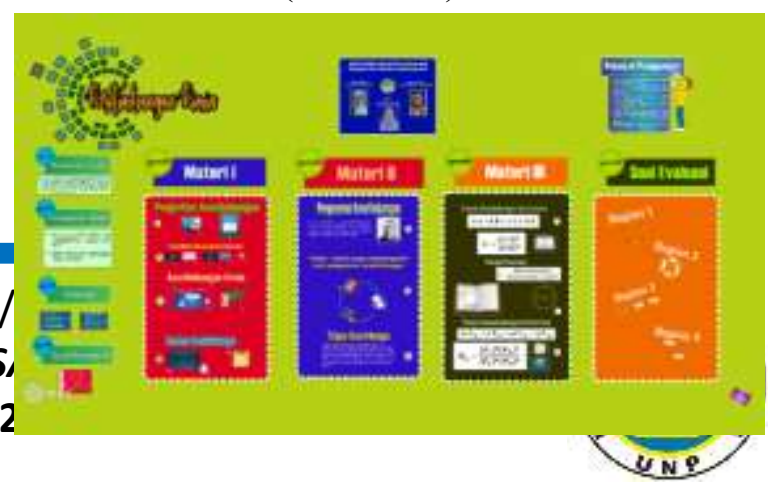




\section{Gambar 1. Home}

\section{b. Petunjuk penggunaan media}

Petunjuk penggunaan media membantu guru maupun sisws menggunakan media pada Prezi. Petunjuk tersebut dimuat pada Gambar 2.

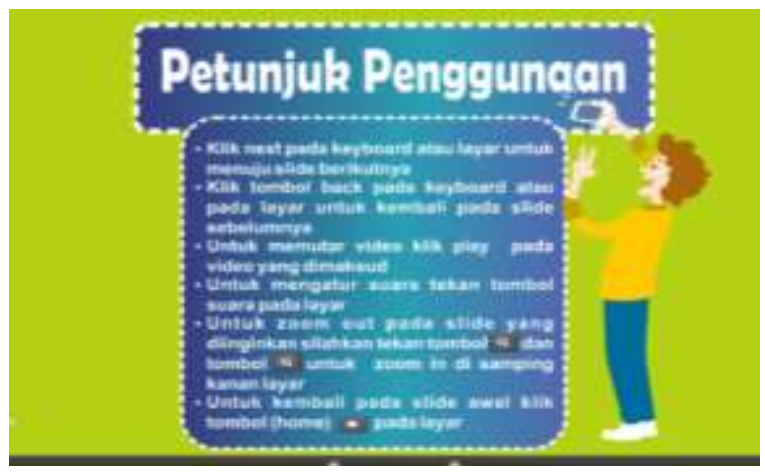

Gambar 2. Petunjuk penggunaan

\section{c. Identitas media}

Pada identitas media dimuat foto pembuat media pembelajaran berbasis tiga level representasi kimia menggunakan Prezi pada materi kesetimbangan kimia. Pada identitas tersebut juga ditambahkan logo UNP. Identitas tersebut dimuat pada Gambar 3.

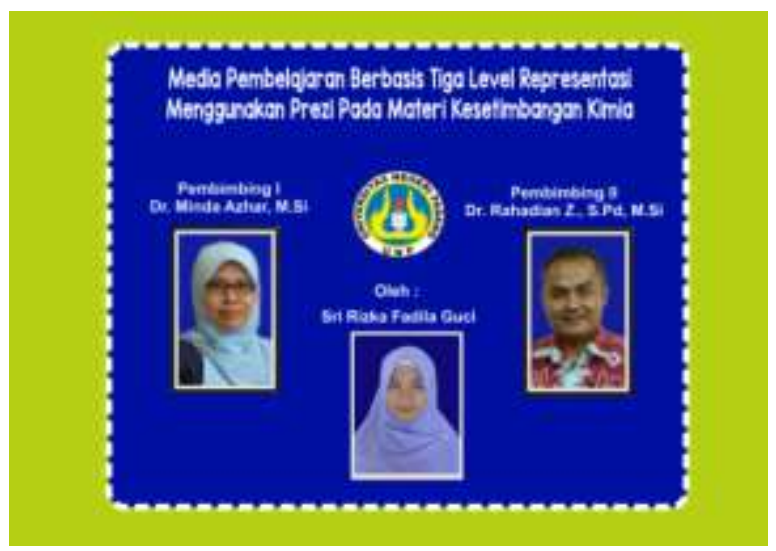

Gambar 3. Identitas media

\section{d. Tampilan Indikator}

Indikator ditulis pada kotak berwarna biru. Indikator berjumlah 10 buah. Pada indikator tersebut domain pada proses kognitiv meliputi menjelaskan (C1) sampai menganalisis (C4), sedangkan domain pada level pengetahuan meliputi pengetahuan faktual, pengetahuan konseptual dan pengetahuan prosedural (Gambar 4)

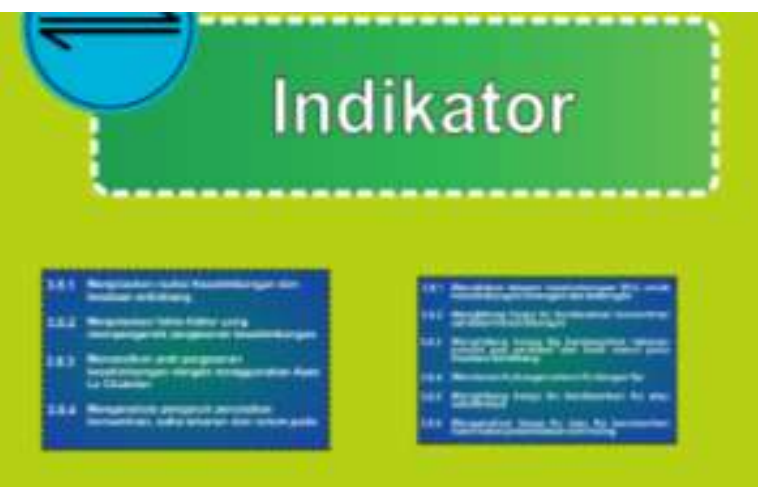

Gambar 4. Indikator

\section{e. Tampilan level representasi kimia}

Tampilan vidio konsep kesetimbangan kimia menampilkan reaksi kesetimbangan antara gas $\mathrm{NO}_{2}$ dan gas $\mathrm{N}_{2} \mathrm{O}_{4}$. Pada level makroskopik data dituangkan dalam bentuk grafik. Pada level submikroskopik berupa gambar molekul $\mathrm{NO}_{2}$ dan $\mathrm{N}_{2} \mathrm{O}_{4}$ yang bergerak dan berubah secara setimbang (setimbang dinamis). Level representasi tersebut dimuat seperti Gambar 5 Level simbolik ini dapat ditulis sebagai persaman reaksi dengan dua tanda panah antara gas $\mathrm{NO}_{2}$ dan gas $\mathrm{N}_{2} \mathrm{O}_{4}$.

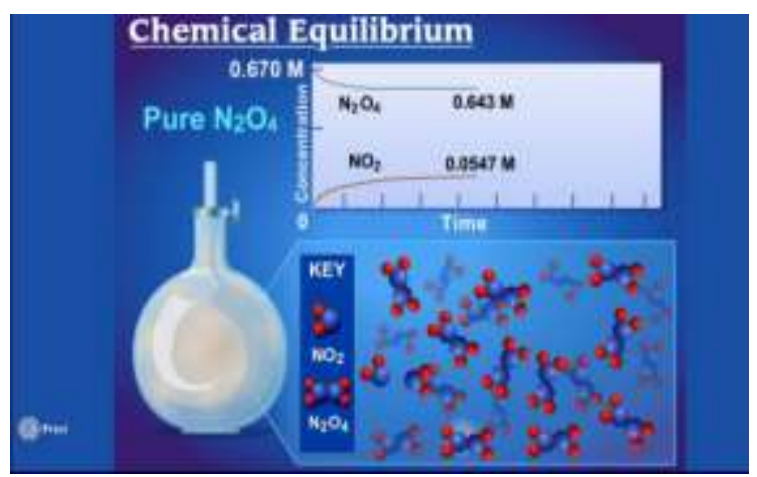

Gambar 5. Konsep kesetimbangan kimia yang memperlihatkan level representasi

Gambar 6 adalah tampilan faktor-faktor yang mempengaruhi kesetimbangan kimia. Pada media ini dimpilkan pengaruh tekanan terhadap arah pergeseran kesetimbangan . pada level makrokopis akan tampak perubahn warna dari $\mathrm{I}_{2}$ gas menjadi 2I, sedangkan pada level simbolik ini ditampilkan persamaan reaksi dengan dua arah bolak balik antara $\mathrm{I}_{2}$ gas dengan 2I gas dan pada level submikrospik ditampilkan pergerakan 
molekul pada saat tekanan diperbesar atau diperkecil.

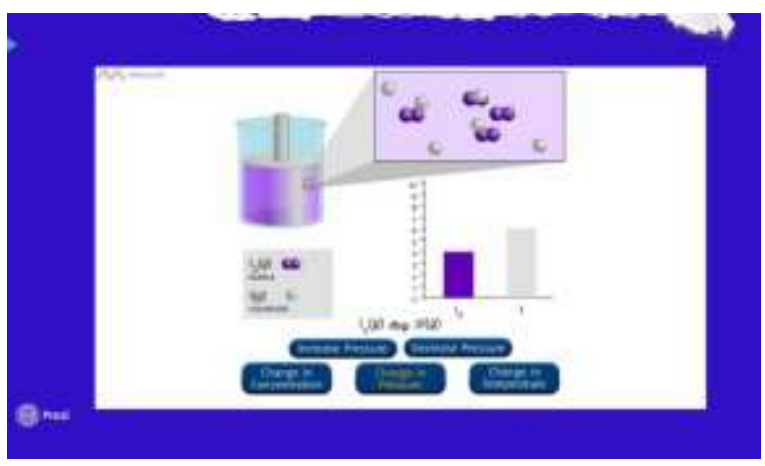

Gambar 6. Faktor yang mempengaruhi kesetimbangan kimia

\section{f. Tampilan evaluasi}

Pada Gambar 7 dimuat beberapa soal untuk menguji kemampuan siswa terhadap pemahaman konsep.

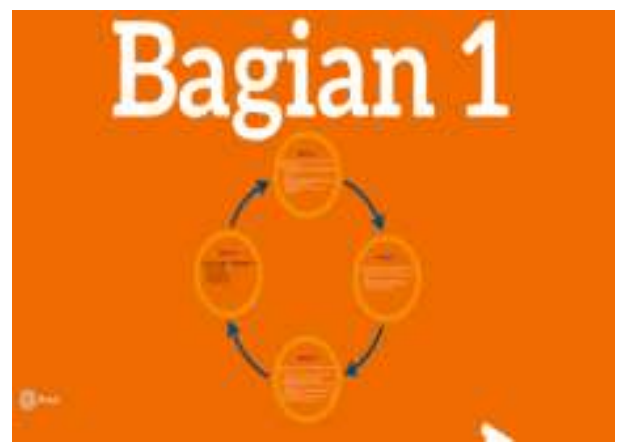

Gambar 7. Soal Evaluasi (Bagian 1)

3.Tahap develop (pengembangan)

Tahap ini bertujuan untuk menghasilkan media pembelajaran berbasis tiga level representasi menggunakan Prezi yang valid dan praktis digunakan. Tahap ini terdiri dari tiga langkah yaitu uji validitas, revisi, dan praktikalitas. Uji validitas bertujuan untuk mengungkapkan validitas dari media pembelajaran yang dikembangkan. Validasi dilakukan oleh tiga orang dosen dan tiga orang guru kimia. Tahap revisi bertujuan untuk memperbaiki media pembelajaran yang dianggap masih kurang tepat oleh validator sebelum produk diujicoba. Media pembelajaran yang sudah diperbaiki kemudian diberikan kembali kepada validator untuk didiskusikan lebih lanjut sebelum diujicoba. Revisi dihentikan apabila validator sudah menyatakan modul yang dibuat sudah valid.

Uji praktikalitas produk dilakukan kepada guru kimia di SMAN 12 Padang dan SMA Pembangunan Laboratorium UNP dan siswa SMA Pembangunan Laboratorium UNP. Uji praktikalitas ini bertujuan untuk mengetahui praktikalitas media pembelajaran yang dikembangkan meliputi manfaat, kemudahan penggunaan, dan efisiensi waktu pembelajaran menggunakan media pembelajaran tersebut. Kepraktisan modul dilakukan dengan menggunakan angket praktikalitas.

\subsection{Validitas media}

Validitas media pembelajaran yang dikembangkan memiliki nilai 0,89 dengan kategori kevalidan sangat tinggi. Validitas ini terdiri atas empat komponen, yaitu komponen kelayakan isi, kebahasaan, penyajian dan visualisasi.

Komponen kelayakan isi memiliki rata-rata momen kappa 0,89 dengan kategori kevalidan sangat tinggi yang berarti bahwa materi pada media pembelajaran berbasis tiga level representasi menggunakn Prezi telah sesuai dengan komptensi inti dan kompetensi dasar. Selain itu, isi materi pada media pembelajaran berbasis tiga level representasi menggunakan Prezi sudah sesuai dengan tujuan pembelajaran yang akan dicapai. Kategori kevalidan sangat tinggi ini juga menunjukkan bahwa kebenaran substansi materi pada media pembelajaran sudah benar. Kebenaran substansi materi perlu diperhatikan untuk menghindari adanya kesalahan konsep. Materi yang hendak disampaikan dengan media pembelajaran haruslah mengandung kebenaran dan disampaikan dengan cermat dan tepat (Prawoto ,1989)

Komponen kebahasaan berkenaan dengan penggunaan kalimat, kejelasan informasi dan kesesuaian bahasa/tulisan dengan kaidah Bahasa Indonesia yang baik dan benar memiliki ratarata momen kappa 0,89. Angka ini termasuk kategori kevalidan sangat tinggi. Hal ini menunjukkan penggunaan Bahasa Indoenesia 
pada media pembelajaran telah baik dan benar. Pembuatan teks pada media pembelajaran menggunakan Bahasa Indonesia yang baik dan benar agar pesan dan informasi yang disampaikan mudah dimengerti oleh siswa. Proses belajar mengajar hakekatnya adalah proses komunikasi yaitu penyampaian pesan dari pengantar ke penerima (Daryanto, 2010).

Rata-rata momen kappa komponen penyajian adalah 0,88 . Angka ini termasuk kategori kevalidan sangat tinggi. Hal ini menunjukkan media pembelajaran berbasis tiga level representasi menggunakan Prezi telah memuat indikator dan tujuan pembelajaran yang jelas. Materi pada media pembelajaran berbasis tiga level representasi menggunakan Prezi juga telah disajikan secara lengkap sesuai dengan urutan pada indikator. Fungsi media pembelajaran harus didukung dengan isi materi yang sesuai dengan konsep dan penyajian materi yang sistematik dan berurutan serta jelas (Suhermin, 2014)

Komponen visualisasi diperoleh rata-rata momen kappa 0,91 dengan kategori kevalidan sangan tinggi (Gambar 8). Hal ini menunjukkan bahwa media pembelajaran berbasis tiga level representasi menggunakan Prezi sudah memiliki bentuk huruf yang jelas, tata letak yang tepat, animasi yang tepat dan desain tampilan yang menarik. Hal ini dapat meningkatkan motivasi siswa dalam proses pembelajaran.

Pada Gambar 8 dapat dilihat bahwa dari semua aspek yang dinilai menunjukkan bahwa nilai momen kappa besar dari 0,81 . Nilai moment kappa 0,81-1.00 memiliki kevalidan sangat tinggi sehingga media pembelajaran terkategori valid. Suatu produk dikatakan valid

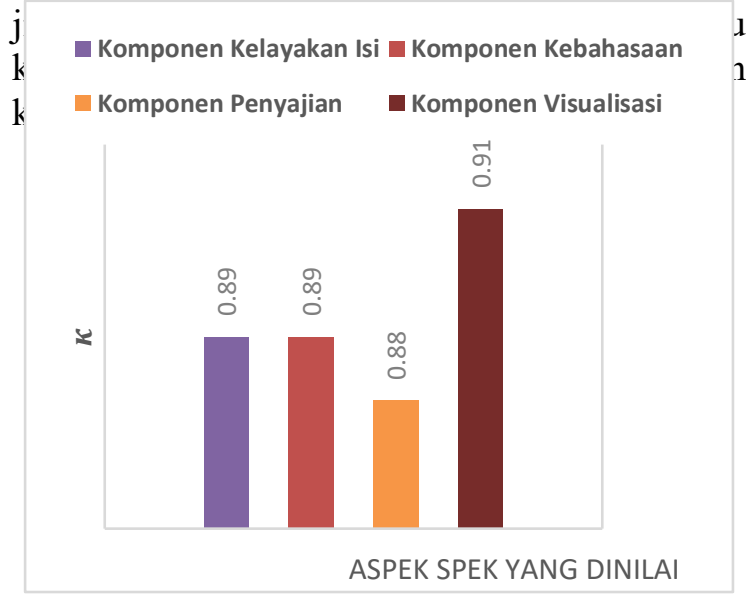

Gambar 8. Kurva nilai moment kappa oleh validator

\subsection{Praktikalitas media}

Praktikalitas media pembelajaran dinilai oleh guru kimia dan siswa SMA kelas XII. Praktikalitas yang dinilai meliputi kemudahan penggunaan, efisiensi waktu penggunaan dam manfaat (Gambar 9). Penilaian praktikalitas oleh guru diperoleh momen kappa sebesar 0,92 dengan kepraktisan sangat tinggi dan oleh siswa sebesar diperoleh momen kappa sebesar 0,80 dengan kepraktisan tinggi. Hal ini menunjukkan media pembelajaran berbasis tiga level representasi menggunakan Prezi yang dikembangkan praktis digunakan di sekolah baik dari aspek kemudahan penggunaan, efesiensi waktu dan manfaat media pembelajaran. Kepraktisan sebuah media pembelajaran mempertimbangkan aspek kemudahan penggunaan, penggunaan waktu yang digunakan dalam pelaksanaan, daya tarik media pembelajaran terhadap minat siswa (Sukardi, 2011).

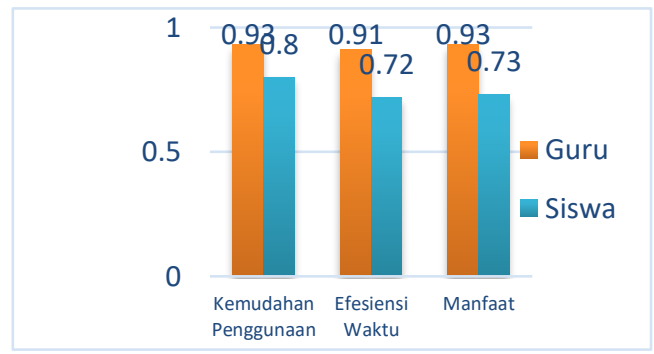

Gambar 9. Kurva momen kappa praktikalitas oleh guru dan siswa.

Berdasarkan hal di atas dapat disimpulkan bahwa media pembelajaran berbasis tiga level representasi menggunakan Prezi pada materi kesetimbangan yang dikembangkan sudah praktis dan dapat digunakan di sekokah.

\section{KESIMPULAN}

Media pembelajaran berbasis tiga level representasi menggunakan Prezi pada materi kesetimbangan kimia telah dihasilkan dengan menggunakan model pengembangan 4-D. Media pembelajaran ini mempunyai tingkat kevalidan sangat tinggi dan kepraktisan sangat tinggi oleh guru dan dan kepraktisan tinggi oleh siswa. 


\section{DAFTAR PUSTAKA}

Arikunto, S. (2008). Dasar-Dasar Evaluasi Pendidikan. Jakarta: Bumi Aksara

Boslaugh, Sarah \& Watters, Paul A. 2008. Statistics in a Nutshell, a desktopquick reference. Beijing, Cambridge, Famham, Köln, Sebastopol, Taipei, Tokyo: O'reilly.

Chandrasegaran, A. L, Treagust, D. F \& Mocerino, M. 2007. The development of A Two-Tier Multiple-Choice Diagnostic Instruent For Evaluating Secondary School Student' Ability To Describe And Explain Reaction Using Multiple Levels of representation. Chemistry education Research and Preavtice, Vol 8(3) hlm. 293

Daryanto. 2010. Media Pembelajaran, Peranannya Sangat Penting Dalam our in Learning: It's Effect on the Retention Tate of Graduate Students, Vol. 6(14) hlm. 1-2

Prawoto. 1989. Media Instruksional Untuk Biologi. Jakarta: Depdikbud.

Sirhan, G. 2007. Learning Difficulties in Chemistry: An Overview. The Journal of Turkish Science Education, 4(2), 2-20

Sugiyono, 2011. Metode Peneletian Pendidikan Pendekatan Kuantitatif, Kualitatif, dan R\&D. Bandung: Penerbit Alfabeta

Suhermin. 2014. "Profil Media Slide Interaktif Berbasis MS Power Point Pada Pokok Bahasan Subtansi Genentika Kelas XII." Jurnal Berkala Ilmiah Pendidikan Biologi. (Volume 3. Nomor 1). Hlm 333-334.

Sukardi. 2011. Evaluasi Pendidikan, Prinsip, Dan Operasionalnya. Yogyakarta: Bumi Aksara.

Sunyono. 2013. Efektifitas Model Pembelajaran Berbasis Multipel Representasi Dalam Membangun Model Mental Mahasiswa Topik Stoikiometri Reaksi. Jurnal Pendidikan Progresif . Vol.3. No. 1. Hlm. 65-79.
Mmencapai Tujuan Pembelajaran.

Yogyakarta: Gava Media

Epinur. 2014. Pengembangan Media

Pembelajaran Kimia pada Materi

Elektrokimia untuk Kelas XII SMA N 8

Kota Jambi dengan Menggunakan Software

Prezi, Vol 6(1) hlm. 22

Hinton, M. E., \& Nakhleh, M. B. 1999. Students' Microscopic, Macroscopic, and Symbolic Representations of Chemical Reaction. The Chemical Educator, 4, 158167

Krause. 2014. Using PREZI-Technology ti promote inquiry-based learning on 'bionics'. Germany: University of Bremen, 142-143

Lukum, Astin. 2015. Metakognisi Mahasiswa Dalam Pembelajaran Kimia, Vol. 21(1)

Olurinola, Oluwakemi. 2015. Col

Trianto. 2012. Mendesain Model Pembelajaran Inovatif-Progresif. Surabaya: Kencana Prenada Media Group.

Tuysuz, M., Ekiz, B., Bektas, O., Uzuntiryaki, E., Tarkin, A., \& Kutucu, E.S. 2011. Preservice Chemistry Teachers' Understanding of Phase Changes and Dissolution at Macroscopic, Symbolic, and Microskopic Levels. Procedia Social and Behavioral Sciences, vol 15, hal. 152-455

Zainul, R., Handayani, D. P., \& Azra, F. (2018, February 1). Pengembangan Multimedia Prezi Berbasis Problem Based Learning (Pbl) Pada Materi Hukum-Hukum Dasar Kimia Kelas X IPA di SMAN 1 Bukittinggi. https://doi.org/10.31227/osf.io/yqpem

Zainul, R., \& Jannah, A. R. (2017, February 6). Pengembangan Media Pembelajaran Asam Basa Menggunakan Aplikasi Android Berbasis Chemistry Triangle Kelas XI SMA/MA.

https://doi.org/10.31227/osf.io/muh8y 